\title{
Rancang Bangun Aplikasi Presensi Menggunakan SmartCard RFID Berbasis Web
}

\author{
Tukadi $^{1}$, Abdullah $^{2}$, dan Syahri Muharom ${ }^{3}$ \\ 1,3Jurusan Teknik Elektro, Institut Teknologi Adhi Tama Suarabaya \\ ${ }^{2}$ Jurusan Teknik Informatika, Institut Teknologi Adhi Tama Suarabaya \\ J1. Arief Rachman Hakim No.100 Surabaya, 60117. \\ e-mail: tukadi@itats.ac.id
}

\begin{abstract}
Abstrak - Presensi karyawan di dalam suatu perusahaan merupakan keperluan administrasi yang penting, karena dapat mempengaruhi besarnya gaji atau honor seorang karyawan dan juga dapat meningkatkan produktivitas perusahaan. Untuk itu dalam presensi diperlukan ketelitian agar tidak merugikan perusahaaan atau karyawan itu sendiri. Maka dari itu pada penelitian ini di ancang aplikasi presensi unntuk penggajian menggunakan Smart Card Rfid Berbasis Web. RFID ini sendiri memiliki kelebihan kecepatan baca data dibandingkan alat sejenisnya, selain itu RFID juga lebih murah dari segi harga dan juga pembacaan informasi lebih mudah karena bentuk dan bidang tidak mempengaruhi pembacaan informasi. Secara fungsional $R F I D$ terdiri 2 bagian inti yaitu RFID reader dan tag RFID. Tag RFID adalah komponen kecil yang menyimpan sebuah informasi rahasia dimana informasi tersebut hanya dapat dibaca menggunakan $R F I D$ reader. Dengan menggunakan Smart Card Rfid berbasis Web dihasilkan proses presensi bisa lebih teliti, akurat dan dapat dimonitoring secara realtime dengan menggunakan web, sehingga dari pihak karyawan ataupun perusahaan dapat memantau presensi dimanapun secara realtime. Agar sistem berjalan dengan baik diperlukan efisiensi pengiriman data, semakin ringan data yang dikirim maka throughtput yang dibutuhkan semakin kecil, dari hasil pengujian didapatkan prosentase keberhasilan $95 \%$. Berdasarkan pengujian error rate yang mana dilakukan percobaan sebanyak 10 kali dapat diketahui bahwa 9 dari 10 data berhasil terkirim dengan baik. Agar tindakan ini tidak membuat sistem menunggu terlalu lama pengiriman data dibatasi dengan waktu 5 detik
\end{abstract}

Kata kunci: Presensi, Karyawan, RFID, Real Time

Abstract-Employee attendance in a company is an important administrative requirement, because it can affect the salary or honorarium of an employee and can also increase company productivity. For that reason, attendance requires accuracy so as not to harm the company or the employee itself. Therefore, in this study, the presence of a presence application for payroll using Web-based Rfid Smart Cards. RFID itself has the advantage of reading data speed compared to similar devices, besides that RFID is also cheaper in terms of price and also easier reading of information because the form and field do not affect the reading of information. Functionally, RFID consists of 2 core parts, namely RFID reader and RFID tag. RFID tags are small components that store confidential information where the information can only be read using an RFID reader. By using Web-based Rfid Smart Cards the presence process can be more thorough, accurate and can be monitored in real time using the web, so that employees or companies can monitor their presence anywhere in real time. In order for the system to run well the efficiency of sending data is needed, the lighter the data sent, the smaller the required throughput, the test results obtained $95 \%$ success percentage. Based on testing the error rate which carried out experiments 10 times it can be seen that 9 out of 10 data were successfully sent well. So that this action does not make the system wait too long the data transmission is limited to 5 seconds

Keywords: Presence, Employees, RFID, Real Time

\section{PENDAHULUAN}

Pada zaman modern yang ada saat ini, perusahaan harus dapat bersaing untuk menghadapi persaingan bebas yang ada. Untuk itu diperlukan kerja sama pada setiap elemen perusahaan yang mana bisa saling mendukung untuk kemajuan perusahaan itu sendiri. Kunci keberhasilan perusahaan juga sangat tergantung dari bagaimana tata kelola manajemen pada perusahaan itu sendiri. Keberhasilan itu sendiri juga ditunjang pada informasi yang signifikan atau relevan dari pengolahan data perusahaan yang akurat[1]. RFID (Radio Frequency IDentification) adalah teknologi komunikasi nirkabel yang digunakan untuk mengambil data, yang dapat dikaitkan dengan atribut identifikasi yang berbeda (nomor seri, posisi, warna, tanggal pembelian, dll.) Dari entitas yang membawa label (tag) RFID. Proses pengumpulan data didasarkan pada pertukaran gelombang elektromagnetik antara tag RFID dan interogator RFID (pembaca). Teknologi Identifikasi Otomatis dan Pengambilan Data (ID Otomatis) ini mampu memberikan granularitas pelabelan lebih lanjut bila dibandingkan dengan barcode dan teknologi ID Otomatis sebelumnya[1].

Presensi karyawan pada perusahaan merupakan suatu hal yang penting. Presensi dikatakan penting karena dapat mempengaruhi besarnya gaji atau honor seorang karyawan dan juga dapat meningkatkan produktivitas perusahaan [2]. Untuk itu dalam presensi dibutuhkan ketelitian agar tidak merugikan salah satu pihak. Pada penelitian ini dibuatlah Rancang Bangun Aplikasi Presensi Untuk Penggajian 
Menggunakan Smart Card Rfid Berbasis Web. RFID ini sendiri memiliki kelebihan kecepatan baca data dibandingkan alat sejenisnya, selain itu RFID juga lebih murah dari segi harga dan juga pembacaan informasi lebih mudah karena bentuk dan bidang tidak mempengaruhi pembacaan informasi[1]. RFID memiliki 2 bagian inti yaitu RFID reader dan tag $R F I D$. Tag $R F I D$ adalah komponen kecil yang menyimpan sebuah informasi rahasia dimana informasi tersebut hanya dapat dibaca menggunakan RFID reader[3]. Dengan menggunakan Smart Card Rfid berbasis Web diharapkan proses presensi bisa lebih teliti, akurat dan dapat dimonitoring secara realtime dengan menggunakan $w e b$, sehingga dari pihak karyawan ataupun perusahaan dapat memantau presensi dimanapun secara realtime.

\section{STUDi PUSTAKA}

Dalam penelitian ini ada beberapa stud i pustaka yang diambil untuk menjelaskan konsep kerja dari bagian sistem yang dirancang, diantaranya:

\section{A. Konsep Sistem Informasi}

Sistem Informasi adalah sebuah proses yang saling berhubungan yang bertujuan untuk mendistribusikan informasi untuk menunjang pengambilan keputusan dan pengawasan dalam suatu organisasi. Tiga aktivitas di dalam sistem informasi akan menghasilkan informasi yang akan dibutuhkan dalam organisasi untuk mengambil keputusan, mengendalikan operasi, menganalisis permasalahan, dan menciptakan produktivitas suatu perusahaan. Aktivitas tersebut adalah Input suatu proses untuk mengumpulkan data dari dalam maupun luar organisasi. Pemrosesan adalah mengubah data input menjadi data yang siap ditampilkan. Output adalah suatu proses untuk mengirimkan informasi yang telah diproses tersebut ke orang-orang yang akan menggunakan atau kepada aktivitas yang akan menggunakan informasi tersebut [3]. Salah satu aktifitas pemrosesan aktifitas dalam presensi yang erat hubungan dengan kelangsungan proses produksi, dimana salah satu produktifitas karyawan dapat dilihat di sini.

\section{Gambaran Umum Internet of Things (IoT)}

Internet of Things merupakan sebuah gagasan yang bertujuan untuk memperluas fungsi dari konektivitas internet yang terhubung secara terus-menerus. Adapun kegunaan yang dimiliki seperti berbagi data, remote control, dan sebagainya, termasuk juga pada benda di dunia nyata. Penerapan IoT pada dunia nyata dapat digunakan untuk memonitoring atau mengkontrol berbagai aspek bahan pangan, elektronik, koleksi, peralatan apa saja, termasuk benda hidup yang semuanya tersambung ke jaringan lokal dan global melalui sensor yang sudah tertanam dan juga selalu aktif[4].

\section{B. Sensor RFID (Radio Frequency Identification)}

RFID (Radio frequency identification) adalah teknologi yang menggabungkan fungsi dari elektromagnetik dan elektrostatik pada frequensi radio dari spectrum elektromagnetik, untuk mengidentifikasi sebuah objek [5]. Teknologi RFID mudah digunakan dan juga sangat cocok untuk operasi sistem otomatis. RFID mengkombinasikan keunggulan yang tidak tersedia dalam perangkat yang hanya dapat dibaca saja (Read Only) atau dapat dibaca dan ditulis (Read/Write), tidak memerlukan kontak langsung maupun jalur cahaya untuk dapat beroperasi dalam pengenalan identitas, dapat berfungsi pada bagian variasi kondisi lingkungan dan menyediakan tingkat integritas data yang tinggi. Sistem RFID terdiri dari tiga kompunen utama yaitu Coupling element yang berisi rangkaian sirkuit dan antena sebagai penangkap sinyal, Housing digunakan sebagai pelindung dari rangkaian sirkuit, antena dan chip agar tidak rusak dan Chip yang berisi data berupa nomor tag atau seri agar dapat dibaca oleh reader. Mekanisme RFID seperti yang terlihat pada gambar 1[6]

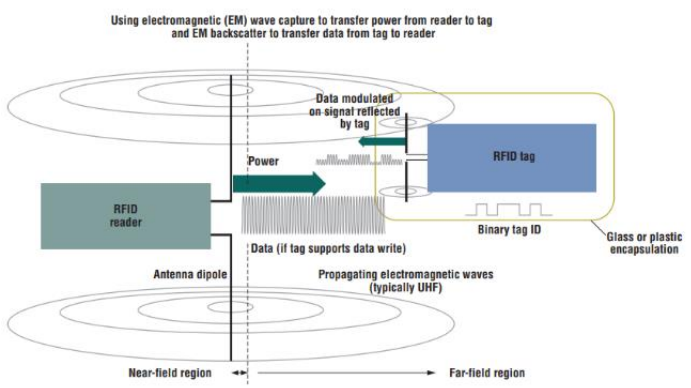

Gambar 1. Mekanisme komunikasi untuk tag RFID[5]

\section{METODE}

Dalam penelitian ini dibagi menjadi beberapa bagian, diantaranya:

\section{A. Perancangan Sistem presensi}

Perancangan sistem presensi untuk penggajian terdapat beberapa hal-hal yang harus di perhatikan yaitu bagaimana cara merancang sistem yang akan diimplementasikan terlebih dahulu dengan cara menentukan diagaram sistem seperti terlihat pada gambar 2 .

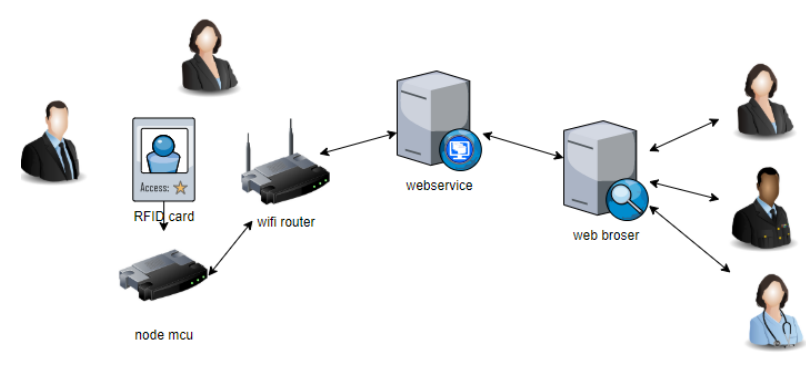

Gambar 2. Sistem Presensi

Setelah perancangan selesai dibuat. Selanjutnya dilakukan pengujian jarak baca Tag pada RFID dan pengujian pengiriman data. Kemudian implementasi dan analisa terhadap pengujian sistem "Smart Attendance System Using RFID”. Rancangan hardware yang digunakan untuk proses presensi menggunakan RFID terdiri beberapa part seperti : NodeMCU ESP8266, MifareReader RC522, Kabel USB, Kartu RFID yang terhubung catu daya. Bentuk rancangan hardware akan dijelaskan beserta dengan fungsi - fungsinya.

NodeMCU ESP8266 yang merupakan suatu modul wifi yang berfungsi sebagai perangkat tambahan pada mikrokontroler. Seperti arduino agar dapat terhubung langsung dengan wifi dan membuat koneksi TCP/IP. NodeMCU ESP8266 berukuran panjang $4.83 \mathrm{~cm}$, lebar $2.54 \mathrm{~cm}$, dan berat 7 gram. Board ini sudah dilengkapi firmware yang bersifat opensource. MifareReader RC522 adalah modul untuk RFID. Modul ini bekerja pada frekuensi 
13,56 MHz. Modul ini memiliki tegangan sebesar 3,3V. Modul ini berfungsi untuk melakukan pembacaan maupun penulisan data.

Untuk menghubungkan antara modul NodeMCU ESP8266 dengan laptop digunakan Kabel USB. Kabel USB ini memiliki dua ujung yang pada satu ujung berupa soket USB dan soket ujung yang berbentuk micro. Kabel USB yang digunakan pada rancangan hardware ini biasa disebut kabel USB empat pin. Jenis kartu yang digunakan RFID Card $13.56 \mathrm{MHz}$ merupakan kartu yang bisa melakukan proses write dan read. Di dalam kartu ini terdapat sebuah chip untuk melakukan pembacaan maupun penulisan. Kartu ini hanya bisa berjalan pada frekuensi $13.56 \mathrm{MHz}$. Kartu ini juga memiliki id yang unik dan berbeda dengan kartu lainnya. Pada kartu ini id bisa berupa angka maupun kombinasi angka dan huruf. Pada rangkaian Gambar 2 ini telah dipasang menjadi satu dengan menggunakan breadboard. Rangkaian ini sudah siap digunakan untuk melakukan proses pengujian fungsionalitas alat.
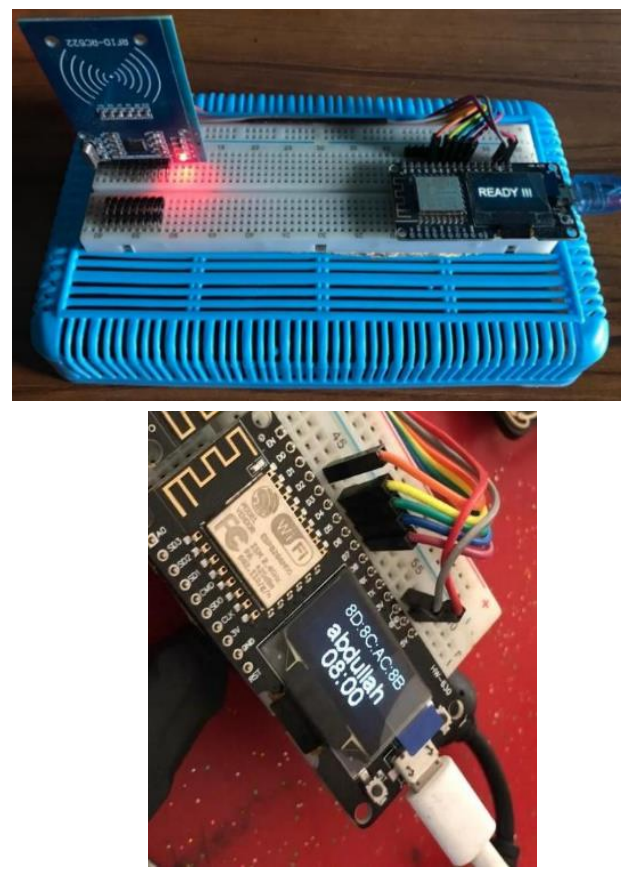

Gambar 3. Rangkaian Alat

Konfigurasi NodeMCU ESP8266 Sebelum menggunakan NodeMCU ESP8266 kita harus melakukan konfigurasi agar bisa melakukan koneksi. Untuk setting itu sendiri kita harus membuat nama ssid dan juga password. Setelah itu selama proses untuk mendapatkan IP Address dan Internet Access. Module akan mengirimkan notifikasi yang dikirimkan melalui serial monitor berupa teks. Proses ini membutuhkan waktu 3-5 detik sampai modul siap untuk digunakan. Setelah alat telah terhubung dengan wifi maka lcd akan menampilkan kata "Ready " yang berarti siap untuk digunakan seperti pada gambar 2 dan Indikator lampu merah menyala pada mifare reader rc522 menandakan modul tersebut siap untuk melakukan pembacaan data.

\section{B. Implementasi Software}

Implementasi software yang digunakan untuk presensi karyawan menggunakan smart card RFID berbasis internet of things (IOT) diantarana adalah membuat tampilan di Arduino IDE dengan memngunakan source code yang sudah ada pada library pada Arduino IDE untuk tampilan proses upload dan tampilan output yang ada di serial monitor. Tampilan web ini dibuat sederhana mungkin sehingga mudah untuk dimengerti. Tampilan web ini sendiri terdiri dari 2 bagian yaitu : untuk admin dan untuk karyawan. Untuk tampilan admin bisa melihat semua presensi karyawan, untuk tampilan karyawan hanya bisa melihat presensi karyawan itu sendiri. Halaman Login merupakan tampilan login pada web yang digunakan untuk proses monitoring karyawan. Setiap admin atau karyawan yang ingin mengecek daftar presensi harus mengisi username dan password pada field yang telah disediakan. Setelah itu sistem akan melakukan validasi terhadap data tadi apakah username dan password yang telah tersimpan di dalam database, jika username dan password tersedia maka login berhasil dan otomatis masuk ke halaman utama web. Apabila login gagal makan akan kembali pada halaman login.

Terdapat authenticatesusers yang mana merupakan library pada laravel. Setelah kita memasukkan email dan password dengan benar, maka otomatis kita bisa masuk ke halaman web dengan catatan email yang kita masukkan telah diaktifkan oleh admin. Apabila email kita belum aktif, maka tidak bisa untuk masuk ke halaman web keseluruhan. Pada halaman web ini telah dapat dilakukan monitoring secara realtime. Untuk web ini ada fitur reward untuk melihat karyawan terbaik dengan menggunakan parameter seperti jam datang tepat waktu maupun banyak jam lembur. Tampilan Menu Payroll System.Pada halaman tampilan menu payroll system terdapat sub gaji. Pada saat diklik gaji akan keluar nama karyawan, jam kerja, total gaji, periode kerja dll. Gaji ini sendiri bisa dilihat oleh karyawan itu sendiri. Tampilan menu tampilan gaji karyawan seperti terlihat pada gambar 4.

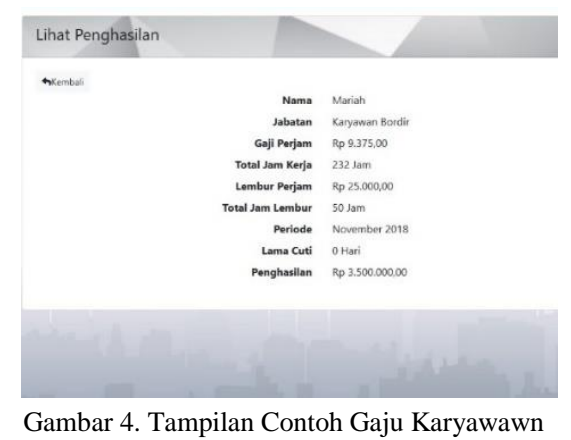

Pada halaman ini terdapat 2 bagian. Bagian pertama adalah tampilan untuk daftar presensi karyawan, untuk bagian kedua adalah daftar reward karyawan. Pada halaman admin bisa melihat daftar lengkap presensi karyawan sedangkan untuk halaman karyawan hanya bisa melihat presensi nya sendiri. Implementasi Database

Pada implementasi database ini akan dijelaskan singkat beberapa table serta fungsinya. Database yang digunakan adalah PHP MYAdmin. Database ini sendiri sebagai media penyimpanan data. Berikut tabel yang digunakan dalam presensi karyawan menggunakan smart card RFID adalah tabel User, Presensi Karyawan, Penggajian, Reward, Cuti, Jabatan.

\section{HASIL DAN PEMBAHASAN}

Untuk mengetahui apakah alat kita telah bekerja dengan baik maka dibutuhkan pengujian. Selain pengujian terhadap alat juga terdapat pengujian untuk jaringan. Pengujian ini sendiri bertujuan untuk menguji sejauh mana alat yang telah kita buat serta mengecek atau untuk menemukan kesalahan 
yang mungkin bisa terjadi. Apabila saat pengujian terjadi error atau kekurangan masih bisa diperbaiki sebaik mungkin agar sesuai dengan rancangan pada bab sebelumnya.

\section{A. Pengujian error Rate Saat Presensi}

Pengujian error rate dilakukan untuk mengetahui seberapa besar kemungkinan error saat melakukan presensi. Pengujian ini juga untuk mengetahui berapa waktu yang dibutuhkan oleh sistem agar dapat menampilkan informasi bahwa presensi telah berhasil. Banyak faktor yang mempengaruhi seperti jarak, jaringan dll. Untuk pengujiannya bisa dilihat pada Tabel 1 .

Tabel 1. Pengujian Error Rate

\begin{tabular}{cccc}
\hline No & Waktu & Status & Keterangan \\
\hline 1 & 0.8 & Berhasil & Success \\
2 & 0.7 & Berhasil & Success \\
3 & 0.5 & Berhasil & Success \\
4 & 1.2 & Berhasil & Success \\
5 & 1.1 & Berhasil & Success \\
6 & 0.9 & Berhasil & Success \\
7 & 0.7 & Berhasil & Success \\
8 & 0.7 & Berhasil & Success \\
9 & 1.1 & Berhasil & Success \\
10 & 5.0 & Gagal & Request Time Out \\
\hline
\end{tabular}

Berdasarkan hasil pada Tabel 1 percobaan dilakukan sebanyak 10 kali, yang mana dapat diketahui bahwa 9 dari 10 data berhasil terkirim dengan baik. Penyebab terjadinya kegagalan pengiriman data adalah dikarenakan alat tidak mendapat koneksi internet yang cukup untuk mengirimkan data sehingga data tersebut tidak dapat terkirim ke server. Hal ini membuat sistem menunggu terlalu lama, maka dari itu untuk pengiriman data dibatasi dengan waktu 5 detik.

\section{B. Pengujian Jarak Baca RC55 MifareReader}

Pengujian ini dimaksudkan untuk mengetahui seberapa jauh jarak pembacaan data oleh mifarereader RC522. Dengan jarak tertentu selalu mempengaruhi kecepatan pembacaan datanya. Untuk mengetahui jarak baca yang bagus atau yang cepat maka dilakukan pengujian ini. Pada Tabel 2 adalah contoh pengujian jarak baca.

Tabel 2. Pengujian Jarak Baca Mifarereader RC55

\begin{tabular}{cccccccc}
\hline \multirow{2}{*}{ No. } & Arah & \multicolumn{7}{c}{ Jarak Baca RC55 } \\
\cline { 3 - 8 } & & $0,5 \mathrm{~cm}$ & $1 \mathrm{~cm}$ & $2 \mathrm{~cm}$ & $3 \mathrm{~cm}$ & $4 \mathrm{~cm}$ & $5 \mathrm{~cm}$ \\
\hline 1 & Atas & - & $\mathrm{V}$ & $\mathrm{V}$ & $\mathrm{V}$ & $\mathrm{X}$ & $\mathrm{X}$ \\
2 & Kanan & $\mathrm{V}$ & $\mathrm{X}$ & $\mathrm{X}$ & $\mathrm{X}$ & $\mathrm{X}$ & $\mathrm{X}$ \\
3 & Kiri & $\mathrm{V}$ & $\mathrm{X}$ & $\mathrm{X}$ & $\mathrm{X}$ & $\mathrm{X}$ & $\mathrm{X}$ \\
\hline
\end{tabular}

Pada Tabel 4.8 adalah pengujian untuk menghitung jarak baca rfid terlihat jarak yang bisa diterima mifarereader $R C 522$ adalah 1-3 cm dari atas maupun bawah, sedangkan untuk jangkauan dari kiri dan kanan hanya dapat membaca dengan jangkauan $0.5 \mathrm{~cm}$ saja.

\section{Pengujian Jaringan menggunakan Throughput}

Pengujian jaringan dengan menggunakan throughtput dilakukan dengan cara melakukan pemantauan terhadap jaringan yang digunakan dengan menggunakan software wireshark. Untuk nilai throughtput yang didapatkan tergantung dari kecepatan jaringan yang digunakan dan modul WiFi yang digunakan. Untuk mengetahui beberapa variasi nilai throughput maka dilakukan perhitungan sebanyak 5 kali. Nilai thoughtput dari percobaan sebanyak 5 kali dapat dilihat pada Tabel 3. Pada tabel tersebut terdapat perbedaan beberapa variasi jumlah data yang ditangkap oleh wireshark. Masing-masing percobaan dilakukan selama 60 detik.

\begin{tabular}{cccc}
\multicolumn{4}{c}{ Tabel 3. Pengujian Throughput } \\
\hline Percobaan ke & $\begin{array}{c}\text { Jumlah data } \\
\text { (byte) }\end{array}$ & Waktu (s) & $\begin{array}{c}\text { Through put } \\
\text { (bps) }\end{array}$ \\
\hline 1 & 51966 & 60 & 6928,80 \\
2 & 59966 & 60 & 7995,46 \\
3 & 61852 & 60 & 8246,93 \\
4 & 57966 & 60 & 7728,8 \\
5 & 67236 & 60 & 8964,8 \\
\hline
\end{tabular}

Berdasarkan pengujian throughtput yang dilakukan sebanyak 5 kali pada Tabel 3 maka didapat kesimpulan bahwa nilai throughtput berbanding lurus dengan dengan jumlah data. Semakin besar jumlah data yang terkirim maka jumlah throughtput akan semakin besar.

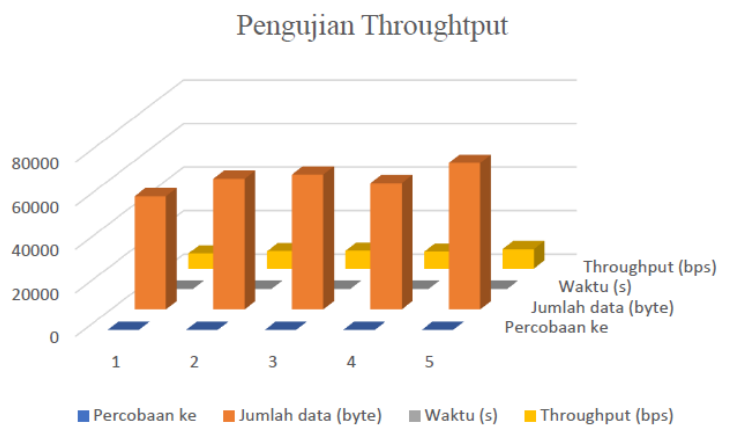

Gambar 5. Hasil pengujian Throughput dengan grafik

\section{KESIMPULAN}

Tujuan dalam penelitian membuat sebuah alat yang digunakan untuk proses presensi karyawan menggunakan RFID berbasis internet of things berhasil. Perancangan hardware memiliki batas kemampuan dan performa masing masing tergantung dari parameter dan sampel yang diuji. Sistem ini sudah dapat dikatakan realtime karena untuk melakukan monitoring sudah dapat dilakukan secara realtime. Pada pengujian pembacaan data oleh mifarereader RC522 dapat disimpulkan bahwa jarak mempengaruhi kecepatan baca. Selain itu jaringan juga dibutuhkan untuk melakukan pembacaan data, karena tanpa adanya jaringan data tidak dapat diolah ataupun disimpan ke dalam database. RFID memiliki kelebihan lebih tahan debu, lebih cepat proses pembacaan data, data yang ditampung lebih banyak dan lebih susah untuk digandakan. Agar sistem berjalan dengan baik diperlukan efisiensi pengiriman data, semakin ringan data yang dikirim maka throughtput yang dibutuhkan semakin kecil, dari hasil pengujian didapatkan prosentase keberhasilan 95\%. Berdasarkan pengujian error rate yang mana dilakukan percobaan sebanyak 10 kali dapat diketahui bahwa 9 dari 10 data berhasil terkirim dengan baik. Penyebab terjadinya kegagalan pengiriman data adalah dikarenakan alat tidak mendapat koneksi internet yang cukup untuk mengirimkan data sehingga data tersebut tidak dapat terkirim ke server. Agar tindakan ini tidak membuat sistem menunggu terlalu lama pengiriman data dibatasi dengan waktu 5 detik 


\section{REFERENSI}

[1] F. Chetouane, "An Overview on RFID Technology Instruction and Application," IFAC-PapersOnLine, vol. 48, no. 3, pp. 382-387, Jan. 2015, doi: 10.1016/j.ifacol.2015.06.111.

[2] S. Kong, J. Zhao, G. Shi, C. Wu, W. Zhao, and T. Liu, The Design and Implementation of the Attendance Management System based on Radio Frequency Identification Technology. Atlantis Press, 2015, pp. 189-192.

[3] "Sistem Informasi manajemen: mengelola perusahaan digital / Kenneth C.Laudan , Jane P.Laudon; penerjemah Chriswan Sungkono , Machmudin Eka P | Dinas Kearsipan dan Perpustakaan Provinsi http://36.67.167.42:8123/inlislite3/opac/detail-opac?id=25724 (accessed Jul. 17, 2020).

[4] J. Kurose and K. Ross, Computer Networking: A Top-Down Approach, 7 edition. Boston: Pearson, 2016.

[5] R. Want, "An Introduction to RFID Technology," IEEE Pervasive Comput., vol. 5, no. 1, pp. 25-33, Jan. 2006, doi: 10.1109/MPRV.2006.2.

[6] K. Finkenzeller, RFID Handbook: Fundamentals and Applications in Contactless Smart Cards, Radio Frequency Identification and NearField Communication. John Wiley \& Sons, 2010. 